\title{
UN ÍNDICE HIDROGEOMORFOLÓGICO (IHG) PARA LA EVALUACIÓN DEL ESTADO ECOLÓGICO DE SISTEMAS FLUVIALES
}

\author{
Alfredo Ollero Ojeda*, Daniel Ballarín Ferrer*, Elena Díaz Bea**, \\ Daniel Mora Mur*, Miguel Sánchez Fabre*, Vanesa Acín Naverac*, \\ María Teresa Echeverría Arnedo*, David Granado García*, Askoa \\ Ibisate González de Matauco**, Lorena Sánchez Gil* \\ y Noelia Sánchez Gil* \\ *Departamento de Geografía y Ordenación del Territorio, Facultad de Filosofía y \\ Letras, Universidad de Zaragoza, C/Pedro Cerbuna, 12, 50009 Zaragoza \\ aollero@unizar.es \\ **Departamento de Geografía, Prehistoria y Arqueología, Universidad del País Vasco
}

\begin{abstract}
Resumen: La dinámica fluvial es la clave no sólo del funcionamiento, sino también del valor ecológico, paisajístico y ambiental de los sistemas fluviales. Si se quiere conservar un río como ecosistema y como corredor ambiental en el territorio se debe proteger ante todo su dinámica hidrogeomorfológica, porque ésta es la que va a garantizar la protección de todos y cada uno de los elementos del sistema y sus relaciones. Por ello, la evaluación del funcionamiento hidrogeomorfológico de los sistemas fluviales es fundamental para determinar su estado ecológico, así como las tendencias previsibles del mismo. Así, se propone un índice de valoración hidrogeomorfológica con el objetivo técnico de la aplicación de la Directiva 2000/60/CE y el no menos importante objetivo científico de la mejora en el conocimiento y diagnóstico de los sistemas fluviales, todo ello en el marco de la urgente y necesaria búsqueda de soluciones a su actual problemática ambiental. El trabajo presentado incluye explicaciones metodológicas para la aplicación del índice, que se estructura en tres parámetros de evaluación: 1) calidad funcional del sistema fluvial, incluyendo a) naturalidad del régimen de caudal, b) disponibilidad y movilidad de sedimentos y c) funcionalidad de la llanura de inundación; 2) calidad del cauce, incluyendo a) naturalidad del trazado y de la morfología en planta, b) continuidad y naturalidad del lecho y de los procesos longitudinales y verticales y c) naturalidad de las márgenes y de la movilidad lateral; y 3) calidad de las riberas, incluyendo a) continuidad longitudinal, b) anchura, estructura y naturalidad y c) interconectividad transversal.
\end{abstract}

\footnotetext{
* Recibido: 11-07-07. Aceptado: 17-10-07.
} 
Palabras clave: Hidrosistemas fluviales, hidrología, geomorfología fluvial, indicadores hidromorfológicos, Directiva 2000/60/CE.

\begin{abstract}
A hydro-geomorphological index (IHG) for river assessment. River dynamics are the key to fluvial systems not only in terms of how they work, but also as regards to the ecological, landscape and environmental value of these systems. If a river is to be preserved as an ecosystem and an environmental corridor in the territory, it is mainly its hydrogeomorphological dynamics that have to be protected, because it is precisely them which will guarantee the protection of each and every element of the system and their relationships. This is the reason why the assessment of the hydrogeomorphological functioning of fluvial systems is essential to determine its environmental condition as well as its foreseeable trends. Thus, a hydrogeomorphological assessment index is proposed with the technical purpose of applying the Directive 2000/60/EU and the equally important scientific objective of improving the knowledge and diagnosis of fluvial systems, all this within the framework of the urgent and necessary search for solutions to its current environmental problems. The work presented includes methodological explanations for the application of the index, which is structured in three assessment parameters: 1) functional quality of the fluvial system, including a) naturalness of the discharge regime, b) sediment availability and mobility and, c) functionality of the floodplain; 2) channel quality, including a) naturalness of channel pattern and morphology, b) continuity and naturalness of the riverbed and longitudinal and vertical processes and, c) naturalness of riverbanks and lateral mobility; and 3) quality of the riparian corridor, including a) longitudinal continuity, b) width, structure and naturalness and, c) cross interconnectivity.
\end{abstract}

Key words: Fluvial hydrosystems, hydrology, fluvial geomorphology, hydromorphological features, Water Framework Directive 2000/60/CE.

\title{
1. Introducción
}

Los ríos son sistemas naturales de máxima dinámica y complejidad, en ajuste permanente en el espacio y en el tiempo ante las fluctuaciones de los caudales líquidos y sólidos, lo que se traduce en movilidad lateral y vertical (Werritty, 1997). Esta movilidad es un mecanismo de autorregulación y es también el motor de una dinámica ecológica intensa, garante de la riqueza y diversidad de estos sistemas naturales (Malavoi et al., 1998). Pero muchas actividades humanas tienen alta capacidad de modificación del funcionamiento fluvial. El desconocimiento de la dinámica natural de cauces y riberas ha acarreado graves consecuencias ambientales.

La Directiva 2000/60/CEE ofrece, entre otros principios, una nueva perspectiva para la conservación y ordenación de los sistemas fluviales. Así, establece la necesidad de aplicar las medidas necesarias para prevenir el deterioro del estado de las 
aguas superficiales, proteger, mejorar y regenerar todas las masas de agua con objeto de alcanzar un buen estado para las naturales y un buen potencial ecológico para las aguas artificiales y muy modificadas antes de fin de 2015. La aplicación de la Directiva no es sólo una necesidad técnica y de gestión, sino también un reto científico.

La valoración de un determinado sector funcional de un sistema fluvial puede abordarse desde diferentes puntos de vista, si el objetivo es diseñar un sistema de valoración que pueda ser útil para la ordenación del territorio, es decir, para fines como la conservación de los corredores ribereños, la gestión sostenible del agua o la zonificación en función del grado de riesgo.

La dinámica fluvial es la clave tanto del funcionamiento como del valor ecológico, paisajístico y ambiental de los sistemas fluviales. Si se quiere conservar un río como ecosistema y como corredor ambiental en el territorio se debe proteger ante todo su dinámica hidrogeomorfológica, porque ésta es la que va a garantizar la protección de todos y cada uno de los elementos del sistema y sus relaciones. Es esa dinámica la que garantiza que haya un corredor ribereño, más complejo y diverso cuanto más activos sean los procesos, y también asegura que las biocenosis acuáticas y ribereñas se asienten, se desarrollen y se desplacen. Para contar con ríos vivos hay que proteger su dinámica (Ollero, 2003). Toda reactivación de la dinámica fluvial en un sector antiguamente móvil pero actualmente estabilizado, se traduce en un plazo muy corto en una reactivación de la dinámica ecológica y, por tanto, en un incremento de la biodiversidad y de la calidad de los ecosistemas acuáticos y ribereños (Malavoi et al., 1998). Cualquier merma o eliminación de la dinámica fluvial genera los efectos inversos, es decir, pérdida de biodiversidad y de calidad ecológica.

Sólo los ríos que mantienen esa dinámica pueden funcionar correctamente como sistemas, es decir, cumplir sus funciones en la naturaleza. Un río sin impactos antrópicos no necesita nada para contar con una dinámica natural activa, ya la tiene sin ninguna duda. Por tanto, si se pretende restaurar un sistema fluvial es preciso recuperar su dinámica natural activa, y para ello hay una serie de requisitos imprescindibles: a) caudales naturales, con fluctuaciones estacionales y procesos extremos, b) crecidas, auténticos motores de dinámica, c) sedimentos que puedan movilizarse, generados tanto en la cuenca como en las propias vertientes con las que choca el cauce y en las propias orillas del mismo, d) ausencia de defensas e infraestructuras que pudieran encorsetar al cauce o dificultar los procesos de erosión, transporte y sedimentación y las relaciones ecológicas, e) presencia de vegetación natural complejamente estructurada que ejerza sus diversas funciones de filtro y controle la dinámica, f) contar, en suma, con un espacio fluvial suficiente, un espacio continuo de cabecera a desembocadura, para mantener las dinámicas naturales longitudinales y verticales, y lo suficientemente ancho para cumplir la dinámica lateral y la conectividad.

La dinámica hidrogeomorfológica debería ser un valor a proteger en sí mismo y un aspecto clave en la valoración del estado ecológico. La valoración hidromorfoló- 

M. ${ }^{a}$ T. Echeverría, D. Granado, A. Ibisate, L. Sánchez y N. Sánchez

gica de cursos fluviales es una necesidad científico-técnica de primer orden en la actualidad.

\section{Antecedentes}

El Bureau of Land Management estadounidense creó un método para definir si un espacio fluvial funciona adecuadamente en cuanto a su hidrología, caracteres geomorfológicos, vegetación y suelos. A esta propuesta se la denominó PFC "proper functioning condition" (Prichard, Dir., 1993, rev. 1995; Moseley, 1999). Ante la PFC los espacios fluviales pueden presentar tres situaciones: a) cumplir la condición, es decir, funcionar adecuadamente, lo cual tiene lugar cuando las riberas disipan la energía de los flujos de crecida reduciendo los procesos de erosión, filtran y capturan sedimentos y ayudan al desarrollo del llano de inundación, retienen y laminan las aguas de crecida y almacenan agua subterránea, estabilizan las orillas, mejoran los hábitats y favorecen el mantenimiento de agua circulante con la temperatura estival apropiada para las comunidades piscícolas, etc.; b) cumplir con riesgo, con ciertas condiciones edáficas, hidrológicas o geomorfológicas susceptibles de degradación; c) no cumplir las funciones citadas por deterioro de la vegetación, alteración o limitación de los componentes hidromorfológicos. Otra iniciativa pionera de valoración partió del U.S. Army Corps of Engineers con el modelo HGM, evaluación hidrogeomórfica de las funciones de humedales, con especial atención a los ribereños (Brinson et al., 1995). Esta metodología se ha aplicado a diferentes territorios, actualizándose recientemente (Smith \& Wakeley, 2002; Hauer et al., 2002).

En muchos otros países han ido apareciendo planes de ordenación, programas de conservación y restauración y normativas diversas que afectan a cauces y riberas. Algunas cuentan con índices de valoración hidromorfológica o, más habitualmente, con índices ecológicos que valoran también algunos parámetros hidromorfológicos.

El River Habitat Survey (RHS), que se desarrolla en el Reino Unido desde 1993, se aplica a tramos de $500 \mathrm{~m}$ de longitud, en cada uno de los cuales se realizan 10 perfiles en los que se observa el sustrato, flujo, caracteres de erosión y sedimentación en el cauce, estructura morfológica y de vegetación en las orillas, así como usos del suelo en el corredor ribereño (Raven et al., 1998). La calidad del hábitat es evaluada a partir de la diversidad de los caracteres (análisis de componentes principales), además de opiniones de expertos y comparación entre casos y con modelos de referencia. Este índice se ha aplicado también en Italia (Buffagni \& Kemp, 2002). Se ha desarrollado un módulo geomorfológico adicional al RHS, llamado GeoRH (Environment Agency, 2003). 
El sistema alemán (LAWA, 2000) es aplicable a cursos medianos y pequeños, realizándose evaluaciones cada 200 ó 400 m de longitud, en función de las dimensiones del curso fluvial. La calidad estructural se establece a partir del análisis de 25 atributos, cada uno de los cuales cuenta con 5 opciones valoradas por expertos. Los atributos se estructuran en seis grupos: morfología del curso, perfil longitudinal, estructura del lecho, perfil transversal, estructura de la orilla y ribera. La escala de valoración es de 1 a 7, calibrándose a partir de las condiciones estrictamente prístinas. Este sistema fue adaptado y mejorado por Fleischhacker \& Kern (2002), que establecen el "estado ecomorfológico", aplicable a ríos navegables.

El sistema de evaluación francés se estructura en tres secciones dedicadas a la calidad fisico-química del agua, al análisis de los seres vivos y al estado del lecho, orillas y cauce mayor. Esta última (SEQ-Physique) parte de la tramificación de los cursos fluviales, continúa con el análisis en el campo y finaliza con el cálculo de índices de calidad en porcentaje sobre una situación ideal. Tartar (2001) señala algunas limitaciones: no sirve para tramos muy antropizados, la sectorialización es dificultosa y resulta imposible definir con precisión un estado de referencia que es básico para el cálculo final.

En suma, los sistemas inglés, francés y alemán, comparados en un trabajo de Raven et al. (2002), valoran caracteres hidromorfológicos muy similares, que pueden resumirse en el siguiente listado: geometría del cauce, perfil longitudinal, perfil transversal, sustrato, vegetación del cauce y restos orgánicos, caracteres de erosión y sedimentación, caracteres del flujo, régimen de caudal, continuidad longitudinal, estructura de las orillas, vegetación ribereña, usos del suelo adyacentes, grado de dinámica lateral y de conectividad del río con el llano de inundación.

Muhar et al. (2004) proponen en Austria los siguientes criterios para la evaluación del estado hidromorfológico: tipo morfológico de río, morfodinámicas, relación cauce-ribera-zona inundable, ocurrencia y extensión de tipos de hábitat, régimen hidrológico, condiciones de flujo, continuidad longitudinal y conectividad lateral. Cada uno de ellos se puntúa de 1 a 5, obteniéndose una media.

En Eslovenia se ha llevado a cabo una experiencia en el río Dragonja, sobre el que se han medido u observado más de un centenar de variables hidrogeomorfológicas (Bizjak \& Mikoš, 2004) en relación con el tipo de cauce, el perfil longitudinal, la sección transversal y las áreas ribereñas. Los resultados califican los tramos en: 1 cursos naturales, 2 algo alterados, 3 moderadamente alterados, 4 alterados, 5 bastante alterados, 6 fuertemente alterados y 7 completamente alterados.

El índice de funcionalidad fluvial italiano (Siligardi, coord., 2003) atiende esencialmente a criterios ligados a la vegetación y se sitúa en una perspectiva ecológica, 

M. ${ }^{a}$ T. Echeverría, D. Granado, A. Ibisate, L. Sánchez y N. Sánchez

ya que se basa en la aplicación y posterior modificación del RCE -Riparian Channel and Environmental Inventory- (Petersen, 1992; Siligardi e Maiolini, 1993). Incluye también como criterios algunos relacionados con aspectos hidromofológicos: configuración de la ribera, actividad erosiva, grado de naturalidad de la sección transversal, diversidad y estabilidad del fondo del cauce, sucesión de pozas, rápidos y meandros.

Otros índices europeos interesantes son el Danish Stream Habitat Index (Pedersen \& Baattrup-Pedersen, 2003) o el método eslovaco, que adapta el índice alemán dando mayor peso a la geomorfología fluvial (Lehotský \& Grešková, 2004).

En Estados Unidos hay varios sistemas de reconocimiento y evaluación de campo de la funcionalidad de sistemas fluviales. Los más destacables son los aplicados en Ohio, Maryland y Vermont. En Ohio se ha puesto en práctica el QHEI (Qualitative Habitat Evaluation Index), que evalúa el hábitat piscícola sin atención a la geomorfología (Rankin, 1991, 1995). El sistema de Maryland responde a las siglas SCA (Stream Corridor Assessment) y se utiliza para valorar el estado físico general del sistema fluvial e indicar sus problemas y posibilidades de restauración (Yetman, 2001). Analiza, junto a parámetros biológicos, indicadores como la incisión, la deposición de sedimentos, la velocidad de la corriente en relación con su profundidad, la protección vegetal de las orillas o la anchura del bosque de ribera. No es una herramienta científica, sino que se desarrolla por voluntarios entrenados. El RGA (Rapid Geomorphic Assessment) de Vermont forma parte de un programa de valoración fluvial más amplio (Rapid Stream Assessment Technique) y proporciona un método de descripción de los procesos de ajuste (en anchura y profundidad, forma en planta y perfil longitudinal) actuales, naturales y/o antrópicos, que se dan en un tramo, determinando su grado de evolución histórica y su tasa de sensibilidad ante posibles cambios en el futuro (Kline et al., 2003). Para determinar esa sensibilidad se utiliza un protocolo de campo que valora la erosividad de los materiales cercanos al cauce, el régimen de sedimentos y de caudal, el encajamiento y pendiente del valle y el grado de desviación respecto al estado de referencia. También se ha empleado mucho por las agencias gubernamentales la metodología de Rosgen (1996) que, apoyada en su clasificación de cursos fluviales (Rosgen, 1994), aporta procesos de evaluación y propuestas de restauración.

Uno de los índices más veteranos e interesantes es el ISC, Index of Stream Condition (Ladson et al., 1996; White \& Ladson, 1999), que se integra en el programa AusRivAS -Australian River Assessment System- (Parsons et al., 2002). Evalúa numerosos caracteres de la corriente fluvial y de su entorno, observando indicadores de cambios graduales o tendencias y también de cambios repentinos e impactos. Los indicadores se estructuran en cinco grupos: hidrológicos, morfológicos, de riberas, de calidad y de vida acuática. El índice está enfocado a evaluar la diferencia entre el estado actual y lo que podría ser bajo condiciones naturales. En Australia hay otras 
iniciativas paralelas de notable interés, como el State of the Rivers Survey (Anderson, 1993), el Habitat Predictive Modelling (Davies et al., 2000), el Rapid Appraisal of Riparian Condition (Jansen et al., 2005) o el River Styles Framework (Brierley \& Fryirs, 2005). Este último constituye una metodología de caracterización geomorfológica muy completa con parámetros de valoración que se centran tanto en la evolución (capacidad de cambio, situaciones irreversibles) como en la condición geomórfica a escala de cuenca y de cauce, resultando de gran utilidad para establecer programas de restauración.

En Sudáfrica, Rowntree \& Ziervogel (1999) han desarrollado una clasificación de la estabilidad del cauce y del estado del mismo a dos escalas de trabajo: una global que define las pautas generales del comportamiento fluvial y otra de detalle donde se analizan los cursos fluviales en el campo a través de un gran número de indicadores geomorfológicos.

En España se han implantado índices de calidad de espacios ribereños como el QBR -Qualitat del Bosc de Ribera- (Munné et al., 1998) o el IHF-GUADALMED (Bonada et al., 2002). García de Jalón y González del Tánago (2005) han elaborado una metodología de evaluación ecológica que ha llevado al índice RQI, de calidad de las riberas (García de Jalón et al., 2006). La Agència Catalana de l'Aigua ha desarrollado el protocolo HIDRI para la valoración de la calidad hidromorfológica de los ríos (Munné et al., dirs., 2006), tomando aspectos del sistema danés-eslovaco (Ovesen et al., 2004).

En Aragón y la cuenca del Ebro se ha trabajado en varios proyectos en los que se ha desarrollado una metodología de tramificación (Ollero et al., 2003; Díaz y Ollero, 2005), caracterización y valoración (Ballarín et al., 2006; Ollero et al., 2006) de cursos fluviales. Los diferentes indicadores hidrogeomorfológicos empleados y los problemas de aplicación de algunos de ellos están en la base del diseño del índice IHG, nueva propuesta de los autores.

\section{El índice hidrogeomorfológico (IHG)}

Las iniciativas de valoración de sistemas fluviales cuentan con condicionantes como la escala de trabajo, la financiación económica, la información previa disponible, la subjetividad de los evaluadores, el sesgo profesional de éstos o de los diseñadores del índice correspondiente, las experiencias previas en la aplicación de otros índices, la dificultad de encontrar modelos de referencia, etc. Además, la utilización de índices importados o alóctonos, probados en otros ríos, puede resultar un fracaso en nuestra área de estudio. Así, por ejemplo, muchos de los indicadores que esta- 

M. ${ }^{a}$ T. Echeverría, D. Granado, A. Ibisate, L. Sánchez y N. Sánchez

blece la Directiva 2000/60/CE son difíciles de evaluar en el ámbito mediterráneo, o requieren importantes matizaciones.

El índice IHG está condicionado también, por tanto, por los aspectos señalados. Precisamente esos condicionantes son los que han llevado a la elaboración de un nuevo índice, que ha tratado de recoger la mayoría de los parámetros evaluados en los antecedentes expuestos, pero que trata también de diferenciarse de todos ellos, de mejorarlos, completarlos o simplificarlos.

Cada autor o equipo de trabajo crea su propio índice, al no estar del todo en acuerdo con cualquier otro sistema de valoración. Con ello nos alejamos de la posibilidad de contar con un índice universal aceptado por todos. Nuestra opinión es que dicho índice es imposible y, por otro lado, que la diversidad de índices está enriqueciendo el debate científico.

Por encima de la coyuntural aplicación de la Directiva 2000/60/CE, los objetivos del nuevo índice IHG de valoración hidrogeomorfológica de sistemas fluviales son fundamentalmente solucionar o reducir los problemas ambientales de los sistemas fluviales, para mejorar y conservar su funcionalidad y naturalidad, así como reivindicar sus valores hidrogeomorfológicos.

El índice IHG se basa en el hecho de que todos los impactos humanos sobre el sistema fluvial, sean directos sobre el cauce o indirectos sobre cuencas y vertientes o diferidos en el tiempo, cuentan con una respuesta en el funcionamiento hidrológico y geomorfológico del sistema y en sus propias morfologías de cauce y riberas. El hecho de que el índice IHG se base en un trabajo de búsqueda o identificación de impactos o presiones puede hacerlo también muy útil en la planificación (Danés, coord., 2005) y en la restauración fluvial.

Previa a la aplicación hay que hacer una buena tramificación del curso fluvial en sectores. Cuanto más pequeños sean éstos, es decir, cuanto mayor sea el detalle en la escala de trabajo, más correcta será la evaluación.

La aplicación del índice IHG requiere la participación de expertos en dinámica fluvial que sean capaces de distinguir en campo y en fotografía aérea presiones e impactos sobre el sistema fluvial que puedan alejar la funcionalidad, continuidad, naturalidad, complejidad y dinámica del mismo respecto del estado de referencia. El uso de fotografías aéreas, con el apoyo de cartografía y documentación, permite aplicar el índice IHG a situaciones pretéritas, lo cual resulta de gran utilidad para evaluar procesos de cambio y comparar niveles de deterioro.

El índice IHG evalúa nueve parámetros ordenados en tres grupos: calidad funcional del sistema fluvial, calidad del cauce y calidad de las riberas. A cada parámetro 
se le aplica un valor inicial de 10 puntos que corresponde a su estado y funcionalidad naturales. A continuación se evalúan los impactos y presiones, lo que implica ir restando puntos a ese valor inicial. En las tablas 1 a 9 se presenta este procedimiento de valoración. En la tabla 10 se reúne todo el proceso de valoración en una ficha única.

\subsection{Valoración de la calidad funcional del sistema fluvial}

La calidad funcional del sistema fluvial se obtiene a partir de la suma de las valoraciones de tres parámetros: la naturalidad del régimen de caudal, la disponibilidad y movilidad de sedimentos y la funcionalidad de la llanura de inundación.

\subsubsection{Naturalidad del régimen de caudal}

Se evalúa el grado de adecuación que el comportamiento del caudal hídrico presenta en relación con el que corresponde a las entradas de agua en la cuenca y su distribución en la red de drenaje, considerando los rasgos del medio natural de la cuenca. Es decir, si el río lleva la cantidad de agua que debería llevar, experimenta cambios estacionales de caudal y crecidas. Partiendo de 10 puntos en situación natural, el sistema y escala de valoración es el que se recoge en la tabla 1. Pueden establecerse valores intermedios si el evaluador lo considera necesario.

El punto de partida del análisis son los datos de caudal de la estación de aforo existente en el sector valorado o la más próxima a él. Si se observan modificaciones en el funcionamiento hidrológico natural se analizan las posibles causas aguas arriba (embalses, derivación a canales de riego, centrales hidroeléctricas, etc.), para lo cual pueden consultarse bases de datos de los organismos de cuenca, cartografía y fotografías aéreas, y puede ser necesario trabajo de campo. Por ejemplo, se buscarán síntomas de sequía en la vegetación o entrada de especies xéricas, si los sedimentos se están compactando o encostrando, si el cauce se ha simplificado y tiende a la incisión lineal... También habría que reconstruir el régimen natural y compararlo con el expresado por los datos de aforo. Dada la complejidad de cálculo de todo este proceso y la posible inexistencia de aforo en los ríos analizados, la evaluación deberá ser en muchos casos cualitativa, apoyada en el mejor conocimiento posible del territorio, en la experiencia del evaluador y en la comparación entre casos.

\subsubsection{Disponibilidad y movilidad de sedimentos}

La función básica de un sistema fluvial es, junto con el transporte hídrico, la movilización de sedimentos aguas abajo. Ese caudal sólido forma parte del ciclo geomor- 

M. ${ }^{a}$ T. Echeverría, D. Granado, A. Ibisate, L. Sánchez y N. Sánchez

Tabla 1. Valoración de la naturalidad del régimen de caudal.

Tanto la cantidad de caudal circulante por el sector como su distribución temporal y sus procesos extremos responden a la dinámica natural, por lo que el sistema fluvial cumple perfectamente su función de transporte hidrológico

Aguas arriba o en el propio sector funcional hay actuaciones humanas (embalses, derivaciones, vertidos, detracciones retornos, trasvases, urbanización de la cuenca, incendios, repoblaciones, etc.) que modifican la cantidad de caudal circulante y/o su

distribución temporal si hay alteraciones muy importantes de caudal, de manera que se invierte el régimen estacional natural, o bien circula de forma permanente un caudal ambiental estable

si hay alteraciones marcadas en la cantidad de caudal circulante, al menos durante algunos periodos, lo cual conlleva inversiones en el régimen estacional de caudales

si hay variaciones en la cantidad de caudal circulante pero las modificaciones del régimen estacional son poco marcadas

si hay algunas variaciones en la cantidad de caudal circulante pero se mantiene bien caracterizado el régimen estacional de caudal si hay modificaciones leves de la cantidad de caudal circulante

fológico, encargándose los ríos del transporte de los materiales desde las vertientes hasta el mar. ¿Lleva el río todos los sedimentos que puede llevar y parece capaz de transportarlos? Se evalúan tanto los déficits sedimentarios derivados de la presencia de presas aguas arriba como otros posibles síntomas locales de dificultades de movilización. También se da importancia a la llegada lateral de aportes sólidos a través de los procesos de vertiente o de procesos fluviales en afluentes que desembocan en el sector. Partiendo de 10 puntos en situación natural, el sistema de valoración se expone en la tabla 2 .

Para evaluar este parámetro es necesario trabajo de gabinete sobre cartografía, fotografía aérea y documentación para localizar las presas, así como planimetría de la cuenca vertiente hasta el inicio del sector y hasta la presa más baja de la cuenca. Igualmente es preciso, sobre cartografía, fotografía aérea y documentación, caracterizar y evaluar el grado de naturalidad de los pequeños afluentes que llegan al sector. Se requiere trabajo de campo en el cauce y márgenes para observar si la forma y tamaño de los sedimentos es variada y está bien distribuida espacialmente, así como posibles indicios de dificultades en la movilidad de sedimentos, como el armouring o acorazamiento del lecho con grandes bloques, frecuente al pie de presas o el embeddedness o cubrimiento de cantos por una pátina de finos, efecto de pérdida de potencia de la corriente. También se comprobará si hay mayor vegetación de ribera que en el pasado, síntoma evidente de anomalías en el transporte sólido. Igualmente se recomienda realizar recorridos de reconocimiento de la línea de conexión vertientes-fondo de valle y de las distintas confluencias de barrancos laterales, con apoyo en fotografía aérea y cartografía. Normalmente las confluencias con afluentes relevantes 
suponen un cambio de sector funcional, por lo que la aportación de éstos se evalúa en el sector aguas abajo de dicha confluencia.

Tabla 2. Valoración de la disponibilidad y movilidad de sedimentos.

El caudal sólido llega al sector funcional sin retención alguna de origen antrópico y el sistema fluvial ejerce sin cortapisas la función de movilización y transporte de esos sedimentos.

sedimentos.

Hay presas con

capacidad de retener

sedimentos en la

cuenca vertiente y en

los sectores superiores

del sistema fluvial

\begin{tabular}{|l|c|}
\hline $\begin{array}{l}\text { si más de un } 75 \% \text { de la cuenca vertiente hasta el sector cuenta } \\
\text { con retención de sedimentos }\end{array}$ & -5 \\
\hline $\begin{array}{l}\text { si entre un } 50 \% \text { y un } 75 \% \text { de la cuenca vertiente hasta el sector } \\
\text { cuenta con retención de sedimentos }\end{array}$ & -4 \\
\hline $\begin{array}{l}\text { si entre un } 25 \% \text { y un } 50 \% \text { de la cuenca vertiente hasta el sector } \\
\text { cuenta con retención de sedimentos }\end{array}$ & -3 \\
\hline $\begin{array}{l}\text { si hay presas que retienen sedimentos, aunque afectan a menos } \\
\text { de un } 25 \% \text { de la cuenca vertiente hasta el sector }\end{array}$ & -2 \\
\hline
\end{tabular}

En el sector hay síntomas 0 indicios de dificultades en la movilidad de los sedimentos (armouring, embeddedness, alteraciones de la potencia específica, crecimiento de ciertas especies vegetales...) y pueden atribuirse a factores antrópicos

Las vertientes del valle y los pequeños afluentes que desembocan en el sector cuentan con alteraciones antrópicas que afectan a la movilidad de sedimentos, o bien su conexión con el valle, la llanura de inundación o el propio lecho fluvial no es continua

\begin{tabular}{|l|c|}
\hline $\begin{array}{l}\text { alteraciones } y / 0 \text { desconexiones } \\
\text { muy importantes }\end{array}$ & -3 \\
\hline $\begin{array}{l}\text { alteraciones y/o desconexiones } \\
\text { significativas }\end{array}$ & -2 \\
\hline $\begin{array}{l}\text { alteraciones y/o desconexiones } \\
\text { leves }\end{array}$ & -1 \\
\hline
\end{tabular}

\subsubsection{Funcionalidad de la llanura de inundación}

La llanura de inundación o cauce mayor es un elemento hidrogeomorfológico construido por el sistema fluvial en su régimen de crecidas. Sus funciones fundamentales son la disipación de energía de las aguas desbordadas y la laminación de los caudales-punta de avenida por almacenamiento temporal de caudal, así como su papel de recinto de decantación de los materiales finos transportados por la corriente desbordada. Una llanura de inundación natural ejerce sin cortapisas las funciones citadas. Pero la ocupación humana de la llanura de inundación puede alterar esa funcionalidad. Además, las actividades humanas que ocupen las llanuras de inundación deberán ser compatibles con la inundación periódica, o bien podemos encontrarnos ante graves situaciones de riesgo. Toda reducción de la funcionalidad natural puede también incrementar la peligrosidad del sistema fluvial aguas abajo o en la margen 

M. ${ }^{a}$ T. Echeverría, D. Granado, A. Ibisate, L. Sánchez y N. Sánchez

opuesta. Partiendo de 10 puntos en situación natural, el sistema de valoración de la funcionalidad de la llanura de inundación se recoge en la tabla 3.

Sobre fotografías aéreas, cartografía y trabajo de campo es preciso inventariar todos los elementos antrópicos de la llanura de inundación. A continuación se medirán las longitudes y superficies afectadas para poder aplicar la valoración. En cursos fluviales carentes de llanura de inundación por su encajamiento se otorgará el valor 10 si en las paredes o vertientes que los delimitan no hay ningún tipo de cortapisa que impida la elevación natural de las aguas (in-flood) en proceso de crecida. Si no se cumple esa situación ideal el evaluador aplicará penalizaciones en función de la extensión e intensidad de la alteración.

Tabla 3. Valoración de la funcionalidad de la llanura de inundación.

\begin{tabular}{|c|c|c|c|c|c|c|}
\hline \multicolumn{6}{|c|}{$\begin{array}{l}\text { La llanura de inundación puede ejercer sin restricción antrópica sus funciones de disipación } \\
\text { de energia en crecida, laminación de caudales-punta por desbordamiento y decantación de } \\
\text { sedimentos }\end{array}$} & 10 \\
\hline \multicolumn{2}{|c|}{$\begin{array}{l}\text { La llanura de inundación cuenta con } \\
\text { defensas longitudinales que restringen } \\
\text { las funciones naturales de laminación, } \\
\text { decantación y disipación de energía }\end{array}$} & $\begin{array}{l}\text { si son } \\
\text { defensas } \\
\text { continuas }\end{array}$ & & $\begin{array}{l}\text { scontinuas } \\
\text { uperan el } \\
\text { la longitud } \\
\text { anura de } \\
\text { dación }\end{array}$ & \multicolumn{2}{|c|}{$\begin{array}{c}\text { si alcanzan } \\
\text { menos del } 50 \% \\
\text { de la longitud } \\
\text { de la llanura de } \\
\text { inundación } \\
\end{array}$} \\
\hline \multicolumn{2}{|c|}{$\begin{array}{l}\text { si predominan defensas directa- } \\
\text { mente adosadas al cauce menor }\end{array}$} & -5 & & -4 & \multicolumn{2}{|c|}{-3} \\
\hline \multicolumn{2}{|c|}{$\begin{array}{l}\text { si están separadas del cauce pero } \\
\text { restringen más del } 50 \% \text { de la an- } \\
\text { chura de la llanura de inundación }\end{array}$} & -4 & & -3 & \multicolumn{2}{|c|}{-2} \\
\hline \multicolumn{2}{|c|}{$\begin{array}{l}\text { si sólo hay defensas alejadas que } \\
\text { restringen menos del } 50 \% \text { de la } \\
\text { anchura de la llanura de } \\
\text { inundación }\end{array}$} & -3 & & -2 & \multicolumn{2}{|c|}{-1} \\
\hline \multirow{2}{*}{\multicolumn{4}{|c|}{$\begin{array}{l}\text { La llanura de inundación tiene obstáculos (defensas, vías de } \\
\text { comunicación elevadas, edificios, acequias...), generalmente } \\
\text { transversales, que alteran los procesos hidrogeomorfológicos de } \\
\text { desbordamiento e inundación y los flujos de crecida }\end{array}$}} & \multicolumn{2}{|c|}{$\begin{array}{l}\text { si hay abundantes } \\
\text { obstáculos }\end{array}$} & -2 \\
\hline & & & & \multicolumn{2}{|c|}{$\begin{array}{l}\text { si hay obstáculos } \\
\text { puntuales }\end{array}$} & -1 \\
\hline \multirow{3}{*}{$\begin{array}{l}\text { La llanura de inundación } \\
\text { presenta usos del suelo que } \\
\text { reducen su funcionalidad } \\
\text { natural o bien ha quedado } \\
\text { colgada por dragados o } \\
\text { canalización del cauce }\end{array}$} & \multicolumn{5}{|c|}{$\begin{array}{l}\text { si los terrenos sobreelevados o impermeabilizados } \\
\text { superan el } 50 \% \text { de su superficie }\end{array}$} & -3 \\
\hline & \multicolumn{5}{|c|}{$\begin{array}{l}\text { si los terrenos sobreelevados o impermeabilizados } \\
\text { constituyen entre el } 15 \% \text { y el } 50 \% \text { de su superficie }\end{array}$} & -2 \\
\hline & \multicolumn{5}{|c|}{$\begin{array}{l}\text { si hay terrenos sobreelevados o impermeabilizados } \\
\text { aunque no alcanzan el } 15 \% \text { de su superficie }\end{array}$} & -1 \\
\hline
\end{tabular}




\subsection{Valoración de la calidad del cauce}

La calidad del cauce se obtiene a partir de la suma de las valoraciones de tres parámetros: la naturalidad del trazado y de la morfología en planta, la continuidad y naturalidad del lecho y de los procesos longitudinales y verticales y la naturalidad de las márgenes y de la movilidad lateral.

\subsubsection{Naturalidad del trazado y de la morfología en planta}

La morfología del cauce es un indicador de naturalidad de toda la cuenca vertiente. Algunos procesos de cambio en esa forma y trazado del cauce pueden res-

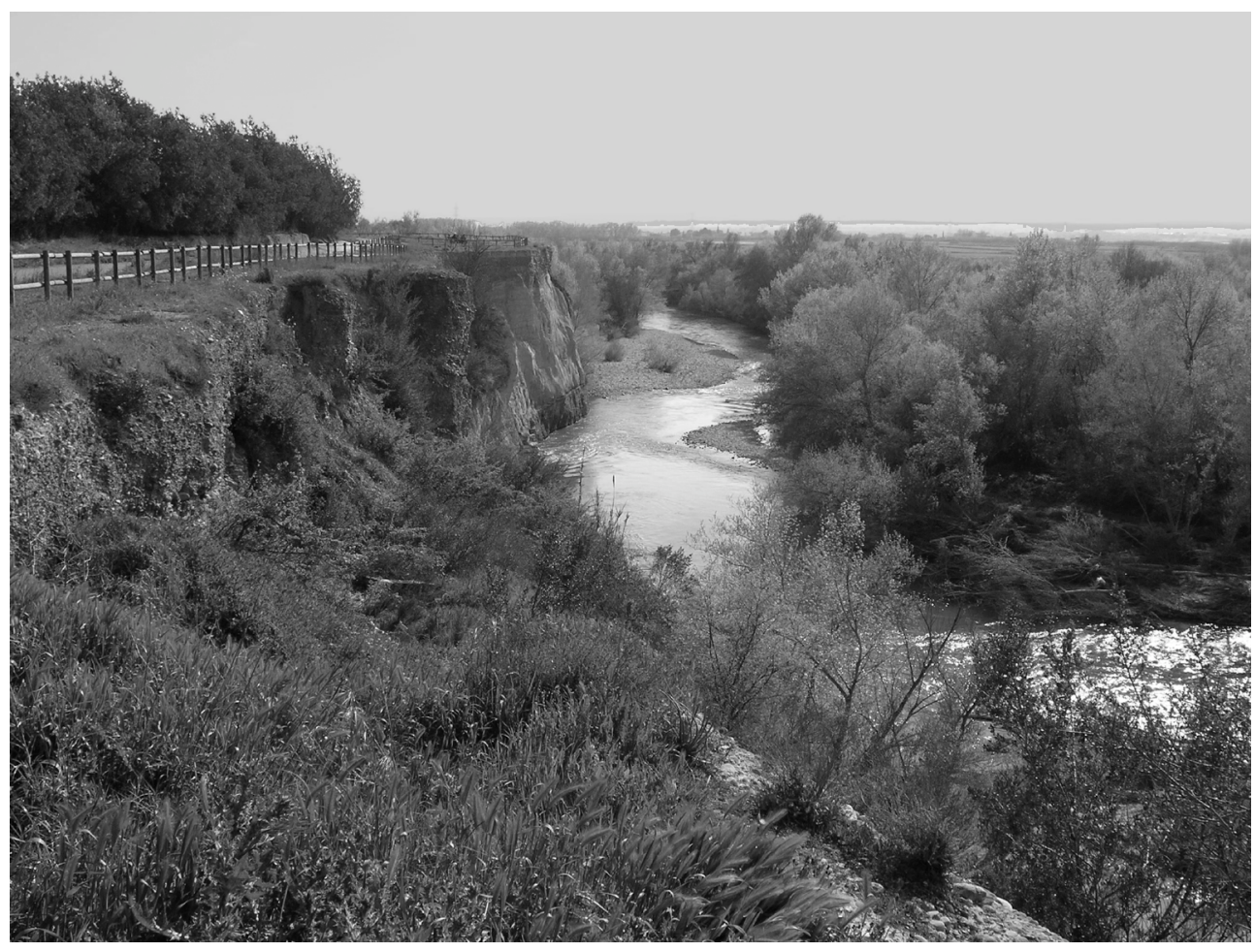

Fotografía 1. Curso bajo del Gállego (Peñaflor). Autor: Alfredo Ollero. Los embalses de cabecera alteran enormemente el régimen del caudal (valoración: 1 punto) y hay importantes retenciones de sedimentos, aunque en el tramo concreto se movilizan bien y la conexión con las vertientes es correcta (valoración: 6 puntos). Afortunadamente, la funcionalidad de la llanura de inundación en este tramo es alta (valoración: 9 puntos), por lo que el valor resultante de la calidad funcional del sistema es de 16 puntos. 

M. ${ }^{a}$ T. Echeverría, D. Granado, A. Ibisate, L. Sánchez y N. Sánchez

ponder a causas antrópicas tanto directas (rectificaciones del cauce) como indirectas (regulación, deforestación, etc.). Han sido y son muy frecuentes por estas causas las tendencias a la simplificación de cauces complejos como los trenzados o anastomosados. La pérdida de naturalidad en el trazado de un cauce es una pérdida de patrimonio natural y de geodiversidad, poniéndose en peligro la dinámica fluvial y el buen estado ecológico. Partiendo de 10 puntos en situación natural, en la tabla 4 se establece la valoración.

Hay que observar si el trazado del cauce es el que corresponde con la pendiente, caudal y litología de la cuenca y del valle o bien ha sido obligado a adaptarse a cambios humanos en la cuenca. Es necesario trabajo con fotografía aérea y consulta de documentación, así como trabajo de campo para encontrar o confirmar los cambios de trazado y su origen humano, con medición en cartografía de la longitud que afectan en relación con la del sector. Así pues, hay que observar en fotografías aéreas y cartografía antiguas los cambios progresivos y consultar documentación sobre la cuenca para dilucidar sus posibles factores antrópicos.

Tabla 4. Valoración de la naturalidad del trazado y de la morfología en planta.

El trazado del cauce se mantiene natural, inalterado, y la morfología en planta presenta los caracteres y dimensiones acordes con las características de la cuenca y del valle, asi como con el funcionamiento natural del sistema

\begin{tabular}{|c|c|c|c|c|c|}
\hline \multirow{2}{*}{$\begin{array}{l}\text { Se han registrado cambios de } \\
\text { trazado artificiales y modificaciones } \\
\text { antrópicas directas de la morfología } \\
\text { en planta del cauce } \\
\qquad \begin{array}{l}\text { si hay cambios drásticos } \\
\text { (desvíos, cortas, relleno de } \\
\text { cauces abandonados, } \\
\text { simplificación de brazos...) }\end{array}\end{array}$} & \multirow{2}{*}{$\begin{array}{c}\text { si afectan a } \\
\text { más del } 50 \% \\
\text { de la } \\
\text { longitud del } \\
\text { sector } \\
-8\end{array}$} & \multirow{2}{*}{$\begin{array}{c}\text { si afectan a } \\
\text { una longitud } \\
\text { entre el } 25 \% \\
\text { y el } 50 \% \\
\\
-7\end{array}$} & $\begin{array}{c}\text { si afectan a } \\
\text { una longitud } \\
\text { entre el } 10 \% \\
\text { y el } 25 \%\end{array}$ & \multicolumn{2}{|c|}{$\begin{array}{l}\text { si afectan a } \\
\text { menos del } \\
10 \% \text { de la } \\
\text { longitud del } \\
\text { sector }\end{array}$} \\
\hline & & & -6 & & 5 \\
\hline $\begin{array}{l}\text { si, no habiendo cambios } \\
\text { drásticos, sí se registran } \\
\text { cambios menores } \\
\text { (retranqueo de márgenes, } \\
\text { pequeñas rectificaciones...) }\end{array}$ & -6 & -5 & -4 & & 3 \\
\hline $\begin{array}{l}\text { si, no habiendo cambios re- } \\
\text { cientes drásticos o menores, } \\
\text { si hay cambios antiguos que } \\
\text { el sistema fluvial ha } \\
\text { renaturalizado parcialmente }\end{array}$ & -4 & -3 & -2 & & 1 \\
\hline \multirow{2}{*}{\multicolumn{4}{|c|}{$\begin{array}{l}\text { En el sector se observan cambios retrospectivos y progresivos en la } \\
\text { morfologia en planta del cauce derivados de actividades humanas en la } \\
\text { cuenca o del efecto de infraestructuras }\end{array}$}} & bles & -2 \\
\hline & & & & & -1 \\
\hline
\end{tabular}




\subsubsection{Continuidad y naturalidad del lecho y de los procesos longitudinales y verticales}

Las infraestructuras transversales al cauce provocan un efecto barrera, rompiendo la continuidad longitudinal del mismo, embalsando la corriente y provocando procesos de incisión aguas abajo. Tanto esas infraestructuras barrera como diferentes actuaciones humanas en los cauces (dragados, extracciones de áridos, solados, limpiezas de vegetación...) alteran la naturalidad del lecho y los procesos hidrogeomorfológicos longitudinales (sucesión de resaltes y remansos) y verticales (agradación o degradación), pudiendo modificar la granulometría y morfometría de los materiales depositados. Partiendo de 10 puntos en situación natural, la valoración aparece en la tabla 5.

Se localizan e inventarían todas las infraestructuras a partir de fotografías aéreas, cartografías y trabajo de campo, evaluándose sus efectos de embalse. A partir de documentación de los organismos de cuenca y mediante observaciones de campo se localizan zonas del cauce afectadas por dragados, extracciones, solados o limpiezas. Se observa si la sucesión de rápidos y remansos es acorde con la pendiente y geomorfología del lecho, si hay vegetación helófita, macrófitos, algas u otros organismos

Tabla 5. Valoración de la continuidad y naturalidad del lecho y de los procesos longitudinales y verticales.

El cauce es natural y continuo y sus procesos hidrogeomorfológicos longitudinales y

verticales son funcionales, naturales y acordes con las caracteristicas de la cuenca y del

valle, del sustrato, de la pendiente y del funcionamiento hidrológico

\begin{tabular}{|c|c|c|c|c|c|}
\hline $\begin{array}{l}\text { En el sector funcional hay infraestructuras } \\
\text { transversales al cauce que rompen la } \\
\text { continuidad del mismo }\end{array}$ & \multicolumn{2}{|c|}{$\begin{array}{l}\text { si embalsan más } \\
\text { del } 50 \% \text { de la } \\
\text { longitud del sector }\end{array}$} & $\begin{array}{l}\text { si embalsan del } \\
25 \text { al } 50 \% \text { de la } \\
\text { longitud del } \\
\text { sector }\end{array}$ & \multicolumn{2}{|c|}{$\begin{array}{l}\text { si embalsan } \\
\text { menos del } 25 \% \\
\text { de la longitud } \\
\text { del sector }\end{array}$} \\
\hline $\begin{array}{l}\text { si hay al menos una presa de } \\
\text { más de } 10 \mathrm{~m} \text { de altura y sin } \\
\text { bypass para sedimentos }\end{array}$ & \multicolumn{2}{|l|}{-5} & -4 & \multicolumn{2}{|c|}{-3} \\
\hline $\begin{array}{l}\text { si hay varios azudes o al menos } \\
\text { una presa de más de } 10 \mathrm{~m} \text { con } \\
\text { bypass para sedimentos }\end{array}$ & \multicolumn{2}{|l|}{-4} & -3 & \multicolumn{2}{|c|}{-2} \\
\hline si hay un solo azud & \multicolumn{2}{|l|}{-3} & -2 & \multicolumn{2}{|c|}{-1} \\
\hline \multirow{2}{*}{\multicolumn{2}{|c|}{$\begin{array}{l}\text { Hay puentes, vados } u \text { otros obstáculos menores que } \\
\text { alteran la continuidad longitudinal del cauce }\end{array}$}} & \multicolumn{3}{|c|}{ más de 1 por cada $\mathrm{km}$ de cauce } & -2 \\
\hline & & \multicolumn{3}{|c|}{ menos de 1 por cada $\mathrm{km}$ de cauce } & -1 \\
\hline \multirow{3}{*}{\multicolumn{2}{|c|}{$\begin{array}{l}\text { La topografia del fondo del lecho, la sucesión de resaltes y } \\
\text { remansos, la granulometría-morfometría de los materiales o } \\
\text { la vegetación acuática o pionera del lecho muestran } \\
\text { síntomas de haber sido alterados por dragados, } \\
\text { extracciones, solados o limpiezas }\end{array}$}} & \multicolumn{3}{|c|}{$\begin{array}{l}\text { en más del } 25 \% \text { de la longitud } \\
\text { del sector }\end{array}$} & -3 \\
\hline & & \multicolumn{3}{|c|}{$\begin{array}{l}\text { en un ámbito de entre el } 5 \text { y el } \\
25 \% \text { de la longitud del sector }\end{array}$} & -2 \\
\hline & & \multicolumn{3}{|c|}{ de forma puntual } & -1 \\
\hline
\end{tabular}



M. ${ }^{a}$ T. Echeverría, D. Granado, A. Ibisate, L. Sánchez y N. Sánchez

que indiquen que el fondo del lecho ha sido alterado. Se buscan síntomas de incisión en puentes, raíces de las orillas, socavación de escarpes, etc.

\subsubsection{Naturalidad de las márgenes y de la movilidad lateral}

La movilidad del cauce es garantía de dinámica fluvial activa y origen de valores ecológicos y biodiversidad. La dinámica lateral debe ser acorde con la situación natural del tipo de cauce correspondiente y responder a un equilibrio de márgenes con erosión y sedimentación. Las defensas de margen impiden la movilidad lateral del cauce o alteran los procesos de erosión y sedimentación. Partiendo de 10 puntos en situación natural, el modelo de valoración se recoge en la tabla 6.

Sobre fotografías aéreas, cartografía y trabajo de campo es preciso inventariar todos los elementos antrópicos colocados sobre las márgenes del cauce. A continuación se medirán las longitudes afectadas. Igualmente se analizará con detalle en campo la morfología de las márgenes y de sus depósitos sedimentarios en busca de síntomas de alteración de la dinámica lateral. En cursos fluviales encajados en los que la movilidad lateral es muy restringida o prácticamente nula se otorgará el valor 10 salvo que en las paredes o vertientes que constituyen las márgenes haya algún elemento antrópico, en cuyo caso el evaluador aplicará penalizaciones en función de la extensión e importancia del elemento.

Tabla 6. Valoración de la naturalidad de las márgenes y de la movilidad lateral.

El cauce es natural y tiene capacidad de movilizarse lateralmente sin cortapisas, ya que sus márgenes naturales presentan una morfología acorde con los procesos hidrogeomorfológicos de erosión y sedimentación

El cauce ha sufrido una canalización total o hay defensas de margen no continuas o infraestructuras (edificios, vías de comunicación, acequias...) adosadas a las márgenes

\begin{tabular}{|l|c|}
\hline en más del $75 \%$ de la longitud del sector & -6 \\
\hline entre un $50 \%$ y un $75 \%$ de la longitud del sector & -5 \\
\hline entre un $25 \%$ y un $50 \%$ de la longitud del sector & -4 \\
\hline entre un 10 y un $25 \%$ de la longitud del sector & -3 \\
\hline entre un 5 y un $10 \%$ de la longitud del sector & -2 \\
\hline en menos de un $5 \%$ de la longitud del sector & -1 \\
\hline
\end{tabular}




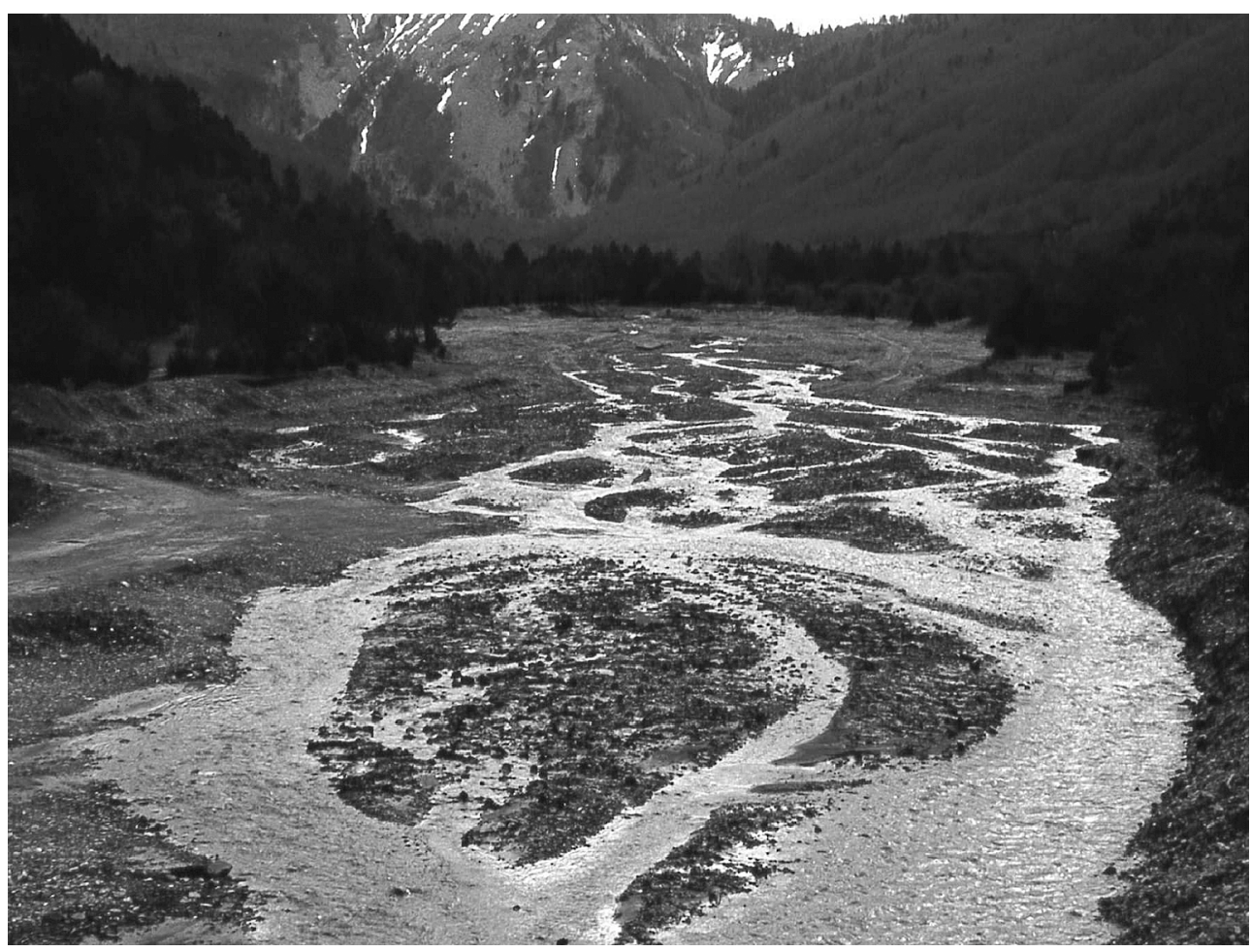

Fotografía 2: Río Belagua. Autora: Elena Díaz. Es el único curso trenzado del Pirineo Navarro, por lo que sus gravas son muy codiciadas y sufre continuas extracciones y dragados que han llegado a hacer aflorar el sustrato y a provocar incisiones superiores a los $2 \mathrm{~m}$. La calidad funcional del sistema es casi perfecta (28 puntos), pero el cauce sufre en naturalidad del trazado (7 puntos) y sobre todo en la naturalidad del lecho (3 puntos) y en la movilidad lateral (5 puntos). Así pues, la calidad del cauce es solo de 15 puntos. Por su singularidad y valor geomorfológico debería ser un tramo a restaurar y proteger.

\subsection{Valoración de la calidad de las riberas}

El corredor ribereño es el espacio en el que se ha movido el cauce menor en las últimas décadas, quedando conformado en muchas ocasiones por masas de vegetación sobre depósitos sedimentarios de granulometría variada y por "anexos fluviales" (canales de crecida, cauces abandonados, etc.). Así pues, el corredor es la banda central de la llanura de inundación, la franja que integra el cauce, su cortejo de bosques ribereños y los paleocauces más recientes. Otros caracteres básicos son un nivel freático alto y su topografía llana pero irregular, labrada por las aguas de desborda- 

M. ${ }^{a}$ T. Echeverría, D. Granado, A. Ibisate, L. Sánchez y N. Sánchez

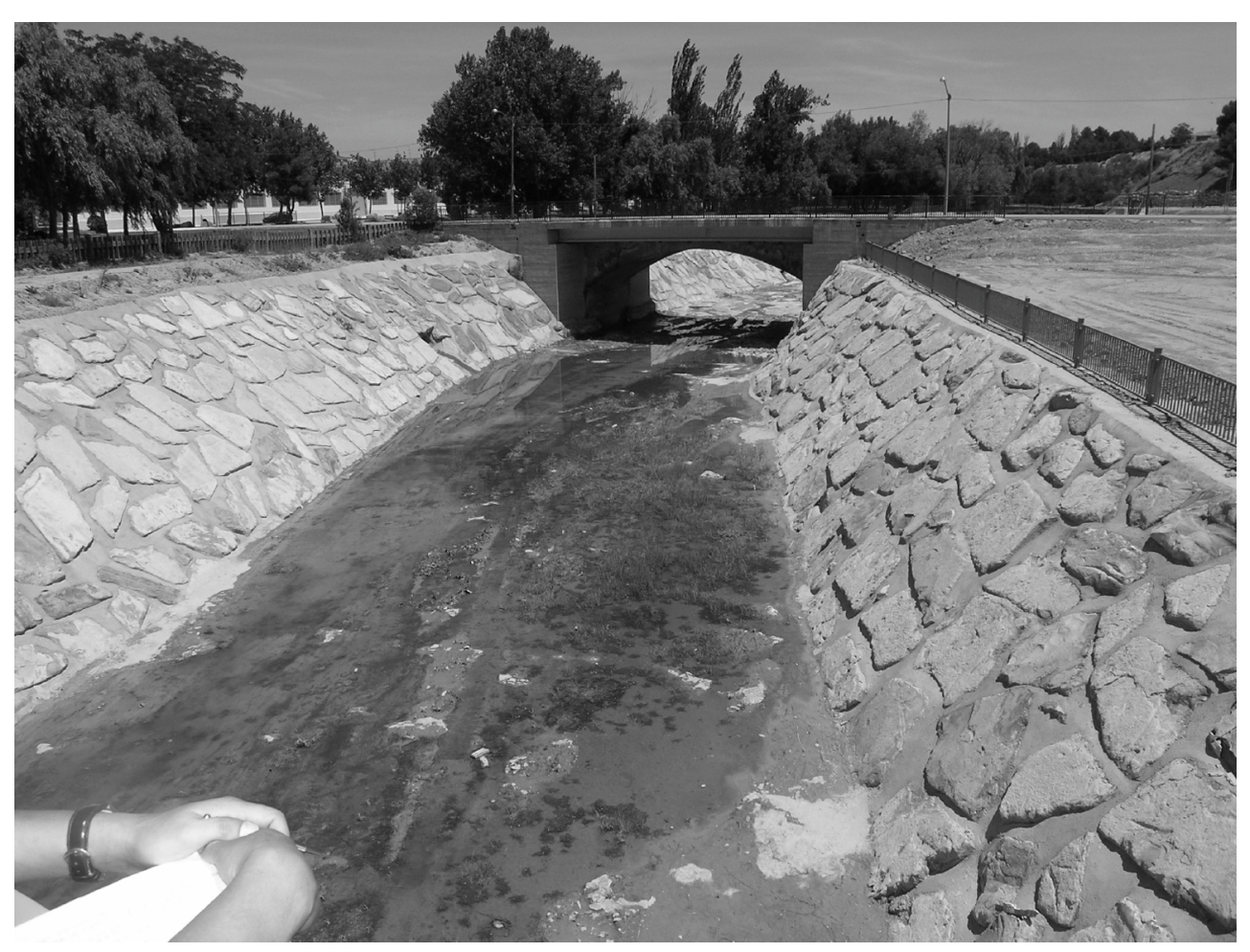

Fotografía 3: Río Arba de Biel en Ejea de los Caballeros. Autor: Alfredo Ollero. En este caso la calidad funcional del sistema aguas arriba es media (18 puntos), ya que hay algunas derivaciones de caudal desde azudes, así como invasión de la llanura de inundación. La canalización urbana es drástica e impermeable, alterando totalmente la calidad del cauce, cuya valoración final suma tan solo 4 puntos.

miento. El papel hidrogeomorfológico principal de la vegetación de ribera es el de filtro de los procesos fluviales, disminuyendo la velocidad de la corriente, favoreciendo la sedimentación diferencial y reforzando y estabilizando las orillas. En este índice se valora esta función hidrogeomorfológica del corredor ribereño, siendo caracteres clave para definir la misma los siguientes: continuidad, anchura, estructura, naturalidad y conectividad.

\subsubsection{Continuidad longitudinal}

La continuidad del corredor ribereño a lo largo del fondo de valle fluvial es una característica clave de su naturalidad y funcionalidad hidrogeomorfológica, ecológica 
y paisajística. Un corredor ribereño continuo y bien conservado es una "autopista ecológica del territorio", entretejiendo conexiones entre diversos ecosistemas y numerosos espacios naturales. Partiendo de 10 puntos en situación natural, el sistema y escala de valoración de la continuidad longitudinal de las riberas es el que aparece en la tabla 7 .

Sobre fotografías aéreas, cartografía y trabajo de campo es preciso inventariar todos los elementos antrópicos que rompen la continuidad del corredor ribereño en cada una de las márgenes del curso fluvial, diferenciando entre usos del suelo permanentes o recuperables. A continuación se medirán las rupturas siguiendo las márgenes del río, evaluando su importancia relativa respecto a la longitud del corredor en el sector.

\subsubsection{Anchura, estructura y naturalidad}

Son tres parámetros fundamentales para evaluar la calidad de un corredor ribereño, que pueden evaluarse de forma conjunta, ya que están claramente relacionados. La anchura potencial de una ribera es un parámetro difícil de estimar, siendo fundamental el conocimiento del terreno por parte de los evaluadores y la visión

Tabla 7. Valoración de la continuidad longitudinal de la ribera.

El corredor ribereño es continuo a lo largo de todo el sector funcional y en ambas márgenes del cauce menor, siempre que el marco geomorfológico del valle lo permita

En el sector funcional hay tramos del corredor ribereño con usos del suelo no recuperables o permanentes (urbanización, naves, granjas, graveras, elementos estables ...) y/o infraestructuras lineales estables transversales al corredor (vías de comunicación, puentes, defensas, acequias...) que rompen la continuidad longitudinal de las riberas naturales

\begin{tabular}{|l|c|}
\hline $\begin{array}{l}\text { si afectan a más del } 60 \% \text { de la longitud } \\
\text { potencial del corredor }\end{array}$ & -7 \\
\hline $\begin{array}{l}\text { si afectan a una longitud entre el } 40 \% \text { y } \\
\text { el } 60 \% \text { del corredor }\end{array}$ & -6 \\
\hline $\begin{array}{l}\text { si afectan a una longitud entre el } 20 \% \text { y } \\
\text { el } 40 \% \text { del corredor }\end{array}$ & -5 \\
\hline $\begin{array}{l}\text { si afectan a una longitud entre el } 10 \% \text { y } \\
\text { el } 20 \% \text { del corredor }\end{array}$ & -4 \\
\hline $\begin{array}{l}\text { si afectan a menos del } 10 \% \text { de la longitud } \\
\text { potencial del corredor }\end{array}$ & -3 \\
\hline $\begin{array}{l}\text { si afectan a más del } 30 \% \text { de la longitud } \\
\text { potencial del corredor }\end{array}$ & -3 \\
\hline $\begin{array}{l}\text { si afectan a una longitud entre el } 10 \% \text { y } \\
\text { el } 30 \% \text { del corredor }\end{array}$ & -2 \\
\hline $\begin{array}{l}\text { si afectan a menos del } 10 \% \text { de la longitud } \\
\text { potencial del corredor }\end{array}$ & -1 \\
\hline
\end{tabular}

En el sector hay superficies con usos del suelo recuperables o no permanentes (choperas, cultivos, zonas taladas, etc.) y/o infraestructuras lineales blandas transversales al corredor (caminos) que suponen discontinuidades de las riberas naturales 

M. ${ }^{a}$ T. Echeverría, D. Granado, A. Ibisate, L. Sánchez y N. Sánchez

retrospectiva con apoyo en fotografías aéreas antiguas que atestigüen dimensiones mayores en el pasado.

Si la continuidad longitudinal (parámetro precedente) ha resultado muy baja, por cuanto quedan superficies de ribera natural muy pequeñas en el sector, es preciso penalizar la aplicación del baremo, ya que, por muy bueno que fuera el estado (en anchura, estructura y naturalidad) de la ribera superviviente, no es representativa de la situación general del sector. Así pues, partiendo de 10 puntos en situación natural, el sistema y escala de valoración de la anchura, estructura y naturalidad de las riberas son los que se recogen en la tabla 8 .

Sobre fotografías aéreas y mapas antiguos se marcará la anchura máxima alcanzada por el corredor ribereño en el sector. A continuación se evaluará la situación actual, comparándose con la potencial o histórica reciente. Para evaluar las presiones

Tabla 8. Valoración de la anchura, estructura y naturalidad de la ribera.

Las riberas supervivientes conservan toda su anchura potencial, su estructura natural (orlas, estratos de vegetación, complejidad de hábitats) y la naturalidad de la vegetación ribereña, de manera que cumplen su papel en el sistema hidrogeomorfológico

La anchura de la

ribera

superviviente ha

sido reducida por

ocupación

antrópica

si la anchura media del corredor ribereño actual es inferior al $50 \%$ de la potencial

si la anchura media del corredor ribereño actual se encuentra entre el $50 \%$ y el $75 \%$ de la anchura potencial

si la anchura media del corredor ribereño actual ha sido reducida pero se mantiene por encima del $75 \%$ de la anchura potencial

Hay presiones antrópicas en las riberas (pastoreo, desbroces, talas, incendios, sobreexplotación del acuífero, recogida de madera muerta, relleno de brazos abandonados, basuras, uso recreativo...) que causan alteraciones de su estructura

\begin{tabular}{|c|c|c|c|c|c|}
\hline \\
\hline & si las alteraciones son muy importantes & -5 & -4 & \multicolumn{2}{|r|}{-3} \\
\hline & si las alteraciones son significativas & -4 & -3 & \multicolumn{2}{|r|}{-2} \\
\hline & si las alteraciones son leves & -3 & -2 & \multicolumn{2}{|r|}{-1} \\
\hline \multirow{2}{*}{\multicolumn{2}{|c|}{$\begin{array}{l}\text { La naturalidad de la vegetación ribereña ha sido } \\
\text { alterada por invasiones o repoblaciones }\end{array}$}} & \multicolumn{3}{|c|}{ si las alteraciones son significativas } & -2 \\
\hline & & \multicolumn{2}{|c|}{ si las alteraciones son leves } & & -1 \\
\hline \multicolumn{3}{|c|}{$\begin{array}{l}\text { si la Continuidad longitudinal ha resultado } 0 \text { (ribera totalmente } \\
\text { eliminada) }\end{array}$} & -10 & \multirow{3}{*}{\multicolumn{2}{|c|}{$\begin{array}{l}\text { si al aplicar estos } \\
\text { puntos el resultado } \\
\text { final es negativo, } \\
\text { valorar } 0\end{array}$}} \\
\hline \multicolumn{3}{|c|}{ si la Continuidad longitudinal ha resultado 1} & -2 & & \\
\hline \multicolumn{3}{|c|}{ si la Continuidad longitudinal ha resultado 2 ó 3} & -1 & & \\
\hline
\end{tabular}


antrópicas sobre la estructura de hábitats, orlas y estratos pueden emplearse bases documentales, fotográficas y cartográficas, pero es fundamental el trabajo de campo, que puede incluir la elaboración de transectos, inventarios y mediciones de detalle. En ese mismo proceso puede determinarse la naturalidad de la vegetación actual o la presencia de especies alóctonas, invasoras o repobladas.

\subsubsection{Interconectividad transversal}

La interconectividad entre hábitats o ambientes dentro del corredor ribereño y en sentido fundamentalmente transversal es un valor ecológico relevante. Si toda la complejidad de la ribera está interconectada, y lo está también con el cauce, las crecidas y los procesos de desbordamiento redistribuirán elementos y nutrientes enriqueciendo todas las interacciones ecológicas. Las defensas longitudinales no sólo alteran la funcionalidad del sistema y la naturalidad de las márgenes, sino que también interumpen las relaciones transversales dentro de la ribera.

Como en el caso del parámetro anterior, si la continuidad longitudinal ha resultado muy baja, es decir, hay muy poca ribera natural superviviente, debe penalizarse la puntuación para no sobrevalorar un corredor muy restringido. Partiendo de 10 puntos en situación natural, el sistema y escala de valoración de la interconectividad transversal se expone en la tabla 9.

Sobre fotografías aéreas, cartografía y trabajo de campo es preciso inventariar todos los elementos antrópicos que rompen la conectividad transversal del corredor ribereño en cada una de las márgenes del curso fluvial, diferenciando entre infraestructuras duras o blandas. A continuación se medirán las longitudes de impacto, evaluando su importancia relativa respecto a la longitud del corredor en el sector. Hay también que observar si han penetrado ciertas especies vegetales (ruderales, climácicas) en bandas internas provocando desconexión dentro de la ribera.

\subsection{Adaptabilidad del índice}

El índice se presenta como ficha única que reúne los nueve parámetros con sus procedimientos de evaluación (tabla 10). Permite valorar de forma integrada la hidrogeomorfología de cada sector del sistema fluvial, para lo cual se suman los 9 valores obtenidos, con un máximo de 90 puntos. Pero también se puede utilizar el índice para valorar sólo la funcionalidad del sistema, o bien la calidad del cauce, o bien la calidad de las riberas. En tales casos se sumarán tan sólo los valores de los 3 parámetros que conforman estas evaluaciones, pudiéndose obtener un máximo de 30 puntos. 
Tabla 9. Valoración de la interconectividad transversal de la ribera.

En las riberas naturales supervivientes se conserva toda la complejidad y diversidad transversal, no existiendo ningún obstáculo antrópico interno que separe o desconecte los distintos habitats o ambientes que conforman el corredor

En el sector hay

infraestructuras lineales,

generalmente longitudinales

o diagonales, duras 0

permanentes (carreteras

defensas, acequias...) que

rompen la interconectividad

transversal del corredor si se distribuyen por todo el sector y la suma de sus longitudes supera la longitud de las riberas

si la suma de sus longitudes da un valor entre el $50 \%$ y el $100 \%$ de la longitud de las riberas

si la suma de sus longitudes da un valor entre el $25 \%$ y el $50 \%$ de la longitud de las riberas

si la suma de sus longitudes es inferior al $25 \%$ de la longitud de las riberas

En el sector hay si se distribuyen por todo el sector y la suma de sus longitudes supera el

infraestructuras $150 \%$ de la longitud de las riberas

ineales de ca-

rácter blando

(pistas, caminos)

que alteran la

interconectividad

transversal del

corredor

si la suma de sus longitudes da un valor entre el $100 \%$ y el $150 \%$ de la longitud de las riberas

si la suma de sus longitudes da un valor entre el $50 \%$ y el $100 \%$ de la longitud de las riberas

si la suma de sus longitudes es inferior al $50 \%$ de la longitud de las riberas o si, no habiendo pistas ni caminos, hay varios senderos

si la Continuidad longitudinal ha resultado 0 (ribera totalmente eliminada)

si la Continuidad longitudinal ha resultado 1

si la Continuidad longitudinal ha resultado 2 ó 3

En función de los objetivos del estudio correspondiente, también es factible ponderar alguno de los parámetros evaluados duplicando o triplicando su valor.

También pueden variarse los valores de cada horquilla para establecer la escala típica de cinco intervalos. Nuestra propuesta inicial es la siguiente: de 75 a 90 puntos calidad hidrogeomorfológica muy buena, de 60 a 74 puntos calidad buena, de 42 a 59 puntos aceptable, de 21 a 41 puntos mala y de 0 a 20 puntos muy mala.

Se ofrece, en definitiva, un producto versátil que puede ser adaptado por los usuarios 


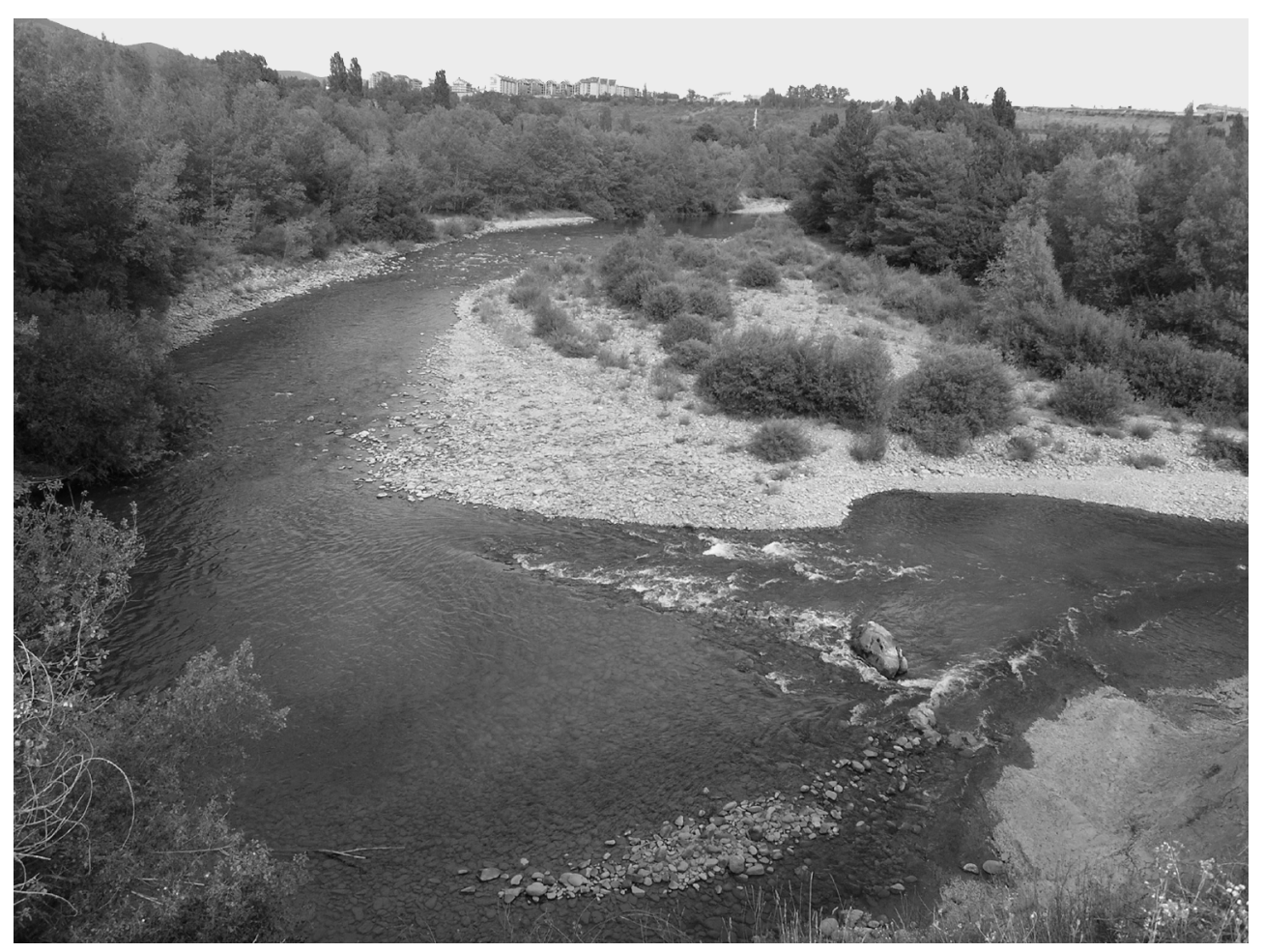

Fotografía 4: Río Aragón aguas abajo de Jaca. Autor: David Granado. La calidad funcional del sistema se ha visto reducida por presas aguas arriba, pero el río se ha recuperado un tanto (19 puntos en total). La calidad del cauce en este ramo concreto es bastante alta (26 puntos). Se observa en la foto que las riberas presentan una buena continuidad y una correcta estructura en orlas, sumándose otros 27 puntos. El valor final, por tanto, sería de 72 puntos. 
A. Ollero, D. Ballarín, E. Díaz, D. Mora, M. Sánchez, V. Acín, M. ${ }^{a}$ T. Echeverría, D. Granado, A. Ibisate, L. Sánchez y N. Sánchez

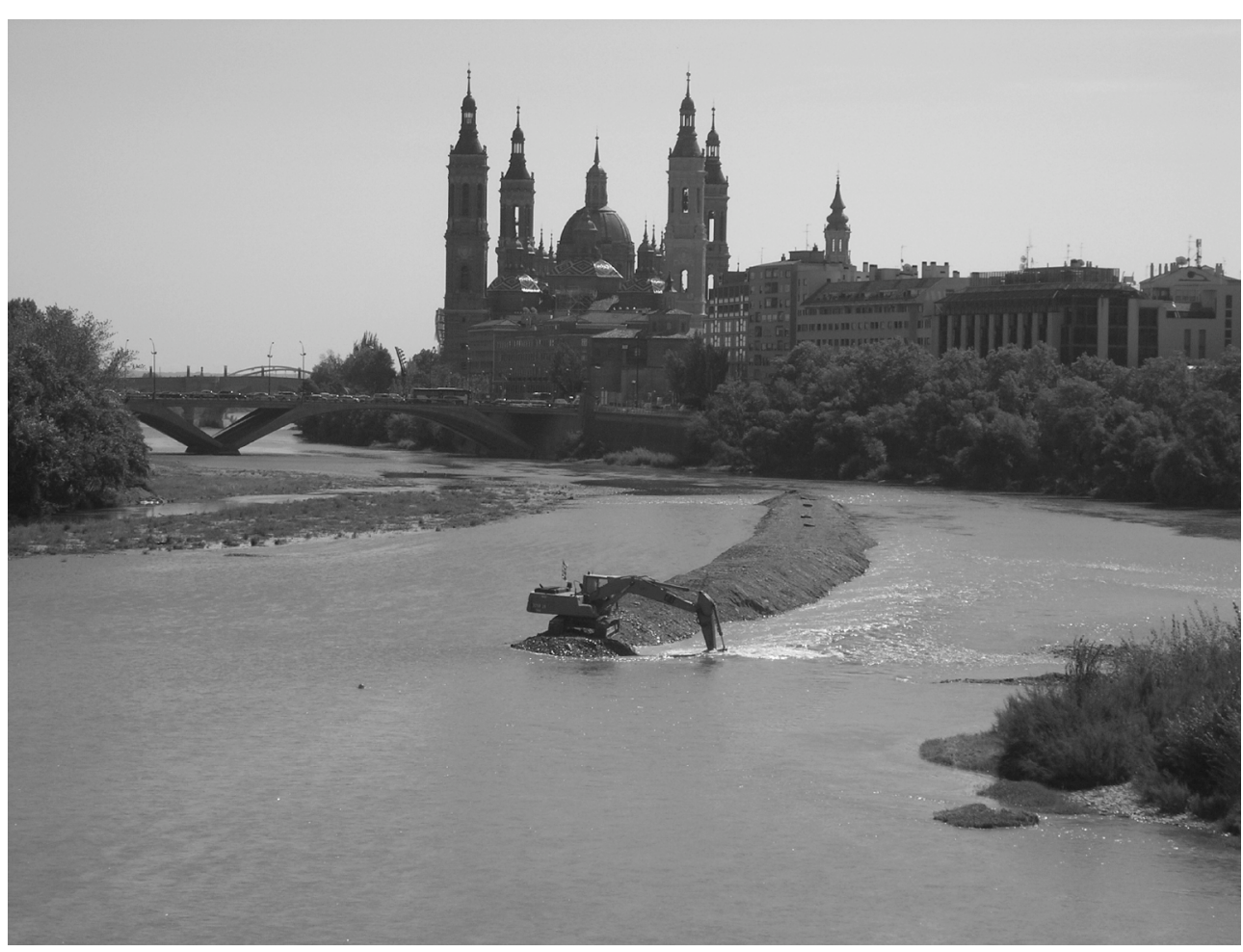

Fotografía 5: Río Ebro en Zaragoza (octubre de 2007). Autor: Alfredo Ollero. La regulación de la cuenca hasta Zaragoza y la pérdida de funcionalidad de la llanura de inundación a causa de la urbanización ya inciden en una calidad funcional baja en este tramo urbano del Ebro (11 puntos). La calidad del cauce se ve muy alterada por la estabilización de las orillas, por el azud construido aguas abajo y por el dragado para abrir un canal de navegación (4 puntos). Las riberas mantienen algunos pequeños enclaves discontinuos y bastante degradados (4 puntos). La valoración final es muy baja: 19 puntos. 


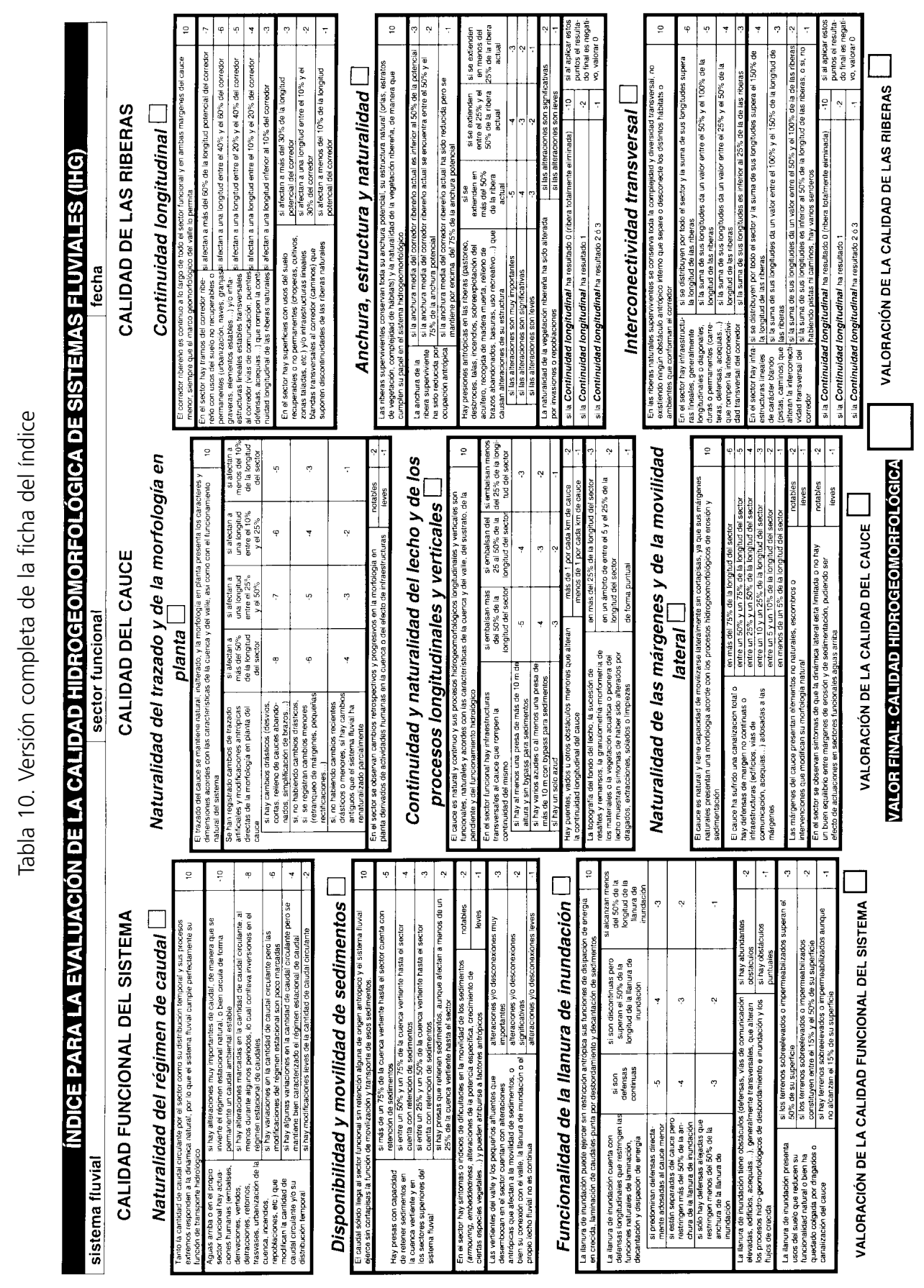



M. ${ }^{a}$ T. Echeverría, D. Granado, A. Ibisate, L. Sánchez y N. Sánchez

\section{Conclusiones}

El índice IHG pretende ser una herramienta de valoración de la calidad hidrogeomorfológica de los sistemas fluviales, simplificando o completando, según los casos, otros índices preexistentes y llenando un vacío metodológico en España, donde los antecedentes son índices de riberas no específicamente hidrogeomorfológicos.

Es un índice basado en las presiones e impactos antrópicos sobre los elementos y funciones hidrogeomorfológicas del sistema fluvial. Puede ser utilizado de forma completa o bien parcialmente para evaluar en exclusiva funcionalidad, calidad del cauce o calidad de la ribera. Puede ser adaptado a otros criterios u objetivos. Los esquemas de valoración que se emplean en cada uno de los nueve parámetros (tablas 1 a 9) pretenden aportar a los evaluadores suficientes criterios como para ejecutar de forma rápida y directa el índice. No obstante, es necesario un conocimiento previo notable del sistema fluvial, siendo imprescindibles las observaciones y mediciones sobre fotografía aérea actual, así como la consulta de documentación sobre la cuenca, cartografía, fotos aéreas antiguas o datos hidrológicos. En campo requiere recorridos longitudinales completando fichas de impactos y mediciones y observaciones de detalle: indicadores de procesos, granulometría, vegetación, restos de crecidas... Se pretende en el futuro ampliar las explicaciones sintetizadas en el presente artículo y elaborar una guía de mayor detalle que incluya fotografías de ejemplos concretos. También se contempla la elaboración de una versión simplificada para evaluadores no expertos.

Aunque no se ha procedido aún a una aplicación sistemática, los casos concretos en los que se ha probado el índice IHG a lo largo de su proceso de definición han dado resultados esperables, perfectamente acordes con los obtenidos en trabajos anteriores.

\section{Agradecimientos}

A Moraia Grau y Marta González del Tánago por sus sugerencias en algunos parámetros del índice. A los organizadores del XIII Congreso de la Asociación Española de Limnología (Barcelona, julio de 2006), en el que se presentó este índice como comunicación oral. Al Área de Planificació de la Agència Catalana de l'Aigua, que está adaptando y aplicando este índice IHG en diferentes estudios. 


\section{Referencias}

Anderson, J.R. (1993). State of the Rivers Project. Queensland, Department of Primary Industries.

Ballarín, D., Mora, D., Díaz Bea, E., Echeverría, M.T., Ibisate, A., Montorio, R., Ollero, A. y Sánchez Fabre, M. (2006). Valoración hidrogeomorfológica de los cursos fluviales de Aragón. Geographicalia, 49, 51-69.

Bizjak, A. \& Mikoš, M. (2004). Synthesis procedure of assessing the hydromorphological status of river corridors: the Dragonja river case study. In Proceedings of $5^{\text {th }}$ International Symposium on Ecobydraulics. Aquatic Habitats: analysis and restoration, Madrid, I, 325-330.

Bonada, N. et al. (2002). Intercalibración de la metodología GUADALMED. Selección de un protocolo de muestreo para la determinación del estado ecológico de los ríos mediterráneos. Limnetica, 21(3-4), 13-33.

Brierley, G.J. \& Fryirs, K.A. (2005). Geomorphology and river management. Applications of the River Styles Framework. Oxford, Blackwell.

Brinson, M.M. et al. (1993). A guidebook for application of bydrogeomorphic assessments to riverine wetlands. Vicksburg, US Army Corps of Engineers, Wetlands Research Program, Technical Report WRPDE-11.

Buffagni, A. \& Kemp, J.L. (2002). Looking beyond the shores of the United Kingdom: addenda for the application of River Habitat Survey in Southern European rivers. Journal of Limnology, 61(2), 199214.

Danés, C. (coord., 2005). Manual para la identificación de las presiones y análisis del impacto en aguas superficiales. Madrid, Ministerio de Medio Ambiente.
Davies, N.M., Norris, R.H. \& Thoms, M.C. (2000). Prediction and assessment of local stream habitat features using large-scale catchment characteristics. Freshwater Biology, 45, 343-369.

Díaz Bea, E. y Ollero, A. (2005). Metodología para la clasificación geomorfológica de los cursos fluviales de la cuenca del Ebro. Geographicalia, 47, 23-45.

Environment Agency (2003). A refined geomorphological and floodplain component. River Habitat Survey FD 1921, GeoRHS fieldwork survey form and guidance manual. Warrington, DEFRA/EA Joint R\&D Project 11793 , prepared by University of Newcastle.

Fleischhacker, T. \& Kern, K. (2002). Ecomorphological survey of large rivers. Koblenz, German Federal Institute of Hydrology.

García de Jalón, D. \& González del Tánago, M. (2005). Critical approach to reference conditions current evaluation methods in rivers and an alternative proposal. In Proceedings COST 626 European Aquatic Modelling Network. Final Meeting. Silkeborg, 91-93.

García de Jalón, D., González del Tánago, M., Lara, F. y Garilleti, R. (2006). Indice RQI para la valoración de las riberas fluviales en el contexto de la Directiva Marco del Agua. Ingeniería Civil, 143, 97-108.

Hauer, F.R., Cook, B.J., Gilbert, M.C., Clairain, E.J.Jr. \& Smith, R.D. (2002). A regional guidebook for applying the bydrogeomorphic approach to assessing wetland functions of intermontane prairie pothole wetlands in the Northern Rocky Mountains Vicksburg, US Army Corps of Engineers, Wetlands Research Program, Technical Report ERDC-EL TR-02-7. 

M. ${ }^{a}$ T. Echeverría, D. Granado, A. Ibisate, L. Sánchez y N. Sánchez

Jansen, A., Robertson, A., Thompson, L. \& Wilson, A. (2005). Rapid appraisal of riparian condition. Version two. River and Riparian Land Management, Technical Guideline 4A. Canberra, Land \& Water Australia.

Kamp, U., Bock, R. \& Hölzl, K. (2004). Assessment of river habitat in Brandenburg, Germany. Limnologica, 34, 176-186.

Kline, M. et al. (2003). Stream Geomorphic Assessment Protocol Handbooks. Remote sensing and field surveys techniques for conducting watershed and reach level assessments. Vermont Agency of Natural Resources.

Ladson, A.R., Doolan, J., White, L.J., Metzeling, L. \& Robinson, D. (1996). Index of Stream Condition as a tool to aid management of rivers. 23th Hydrology and Water Resources Symposium. 325-332. Hobart, Institution of Engineers.

LAWA. 2000. Gewässerstrukturgütebewertung in der Bundesrepublik Deutschland, Verfabren für kleine und mittelgro $e$ Flie gewässer. Berlin, Länderarbeitsgemeinschaft Wasser.

Lehotský, M. \& Grešková, A. (2004). Hydromorphological river survey and assessment (Slovakia). Bratislava, Slovak Hydrometeorological Institute.

Malavoi, J.R., Bravard, J.P., Piégay, H., Héroin, E. et Ramez, P. (1998). Determination de l'espace de liberté des cours d'eau. Lyon, SDAGE Rhône-Méditerranée-Corse.

Moseley, R.K. (1999). Riparian inventory and proper functioning condition assessment of the Rocking $M$ Wildlife Conservation Easement Area. Idaho Department of Fish and Game.

Muhar, S., Unfer, G., Schmutz, S., Jungwirth, M., Egger, G. \& Angermann, K. (2004). Assessing river restoration programmes: habitat conditions, fish fauna and vegeta- tion as indicators for the possibilities and constraints of river restoration. In Proceedings of $5^{\text {th }}$ International Symposium on Ecobydraulics. Aquatic Habitats: analysis and restoration, Madrid, I, 300-305.

Munné, A., Solà, C. y Prat, N. (1998). QBR: un índice rápido para la evaluación de la calidad de los ecosistemas de ribera. Tecnología del agua, 175, 20-37.

Munné, A., Solà, C. y Pagés, J. (2006). HIDRI: Protocolo para la valoración de la calidad bidromorfológica de los ríos. Barcelona, Agència Catalana de l'Aigua.

Newton, B. et al. (1998). Stream Visual Assessment Protocol. Washington, National Water and Climate Center.

Ollero, A. (2003). El Ebro quiere volver a ser libre. Una dinámica fluvial activa es la clave para que haya ríos vivos. Quercus, 213, 34-38.

Ollero, A., Echeverría, M.T., Sánchez Fabre, M., Auría, V., Ballarín, D. y Mora, D. (2003). Metodología para la tipificación hidromorfológica de los cursos fluviales de Aragón en aplicación de la Directiva Marco de Aguas (2000/60/CE). Geographicalia, 44, 7-25.

Ollero, A., Ballarín, D., Díaz Bea, E., Mora, D. y Sánchez Fabre, M. (2006). Calidad hidromorfológica de los ríos de Aragón. Tecnología del Agua, 278, 36-41.

Ovesen, N.B. et al. (2004). Establishment of the protocol on monitoring ad assessment of the hydromorphological elements. Final report. Twinning light Project $\mathrm{n}^{\mathrm{o}}$ TLP 0129.

Parsons, M., Thoms, M.C. \& Norris, R. (2002). Australian river assessment system review of physical river assessment methods. A biological perspective. Monitoring River Health Initiative, Technical Report $n^{0}$ 21, Commonwealth of Australia and University of Canberra. 
Pedersen, M.L. \& Baattrup-Pedersen, A. (2003). Økologisk overvågning $i$ vandløb og på vandløbsnoere arealer under NOVANA 2004-2009. Danmarks Miljøundersøgelser. Teknisk Anvisning fra DMU nr. 21.

Petersen, R.C.Jr. (1992). The RCE: a Riparian, Channel, and Environmental Inventory for small streams in the agricultural landscape. Freshwater Biology, 27, 295-306.

Prichard, D. (Dir.) (1993, rev. 1995). Process for assessing proper conditions. Denver, Bureau of Land Management Service Center.

Rankin, E.T. (1991). The use of the qualitative habitat evaluation index for use attainability studies in streams and Rivers in Ohio. In Gibson, G. (ed.) Biological criteria: research and regulation. EPA 440/5-91005. Washington, D.C., Office of Water, U.S. Environmental Protection Agency.

Rankin, E.T. (1995). Habitat indices in water resource quality assessments. In Davis, W.S. \& Simon, T.P. (eds.) Biological assessment and criteria: tools for water resource planning and decision making, 181-208, Boca Raton, Lewis Publishers.

Raven, P.J., Boon, P.J., Dawson, F.H. \& Ferguson, A.J.D. (1998). Towards an integrated aproach to classifying and evaluating rivers in UK. Aquatic Conservation. Marine and Freshwater Ecosystems, 8(4), 383-393.

Raven, P.J., Holmes, N.T.H., Charrier, P., Dawson, F.H., Naura, M. \& Boon, P.J. (2002). Towards a harmonized approach for hydromorphological assessment of rivers in Europe: a qualitative comparison of three survey methods. Aquatic Conservation. Marine and Freshwater Ecosystems, 12, 405-424.

Rosgen, D.L. (1994). A classification of natural rivers. Catena, 22(3), 169-199.
Rosgen, D.L. (1996). Applied river morphology. Wildland Hydrology Books, Pagosa Springs.

Rowntree, K.M. \& Ziervogel, G. (1999). Development of an index of stream geomorphology for the assessment of river bealth. NAEBP Report Series 7. Pretoria, Institute for Water Quality Studies.

Siligardi, M. (coord., 2003). I.F.F. Indice de funzionalità fluviale. Roma, Agencia Nazionale per la Protezione dell'Ambiente.

Siligardi, M. e Maiolini, B. (1993). L'inventario delle caratteristiche ambientali dei corsi d'acqua alpini: guida all'uso della scheda RCE-2. Biologia Ambientale, VII (30), 18 24.

Smith, R.D. \& Wakeley, J.S. (2001). Developing assessment models. Hydrogeomorphic approach to assessing wetland functions: guidelines for developing regional guidebooks. Vicksburg, US Army Corps of Engineers, Wetlands Research Program, Technical Report ERDC-EL TR-01-30.

Tartar, P. (2001). Mise en oeuvre du système d'évaluation de la qualité physique des cours d'eau sur l'Andelle. Note de synthèse. DIREN Haute-Normandie.

Werrity, A. (1997). Short-term changes in channel stability. In Thorne, C.R., Hey, R.D. \& Newson, M.D. (eds.) Applied fluvial geomorphology for river engineering and management, 47-65, Chichester, Wiley.

White, L.J. \& Ladson, A.R. (1999). An Index of Stream Condition Reference Manual. Melbourne, Department of Natural Resources and Environment.

Yetman, K.T. (2001). Stream corridor assessment survey. Watershed Restoration Division, Annapolis, Maryland Dept. of Natural Resources. 